Article

\title{
'Looking to the Future and the University in an Inclusive and Sustainable Way': A Career Intervention for High School Students
}

\author{
Sara Santilli *(D), Ilaria di Maggio, Maria Cristina Ginevra, Laura Nota and Salvatore Soresi \\ Dipartimento di Filosofia, Sociologia, Pedagogia e Psicologia Applicata (FISPPA), University of Padova, \\ 35139 Padova, Italy; ilaria.dimaggio@unipd.it (I.d.M.); mariacristina.ginevra@unipd.it (M.C.G.); \\ laura.nota@unipd.it (L.N.); salvatore.soresi@unipd.it (S.S.) \\ * Correspondence: sara.santilli@unipd.it
}

Received: 16 September 2020; Accepted: 23 October 2020; Published: 30 October 2020

check for updates

\begin{abstract}
Career guidance needs new perspectives, considering the challenges that characterize our future, and it cannot exist without solidarity, inclusion, and attention to environmental challenges. It should also positively influence stakeholders to invest in the values of the 2030 Agenda recently proposed by the United Nations, and its encouragement to think about some of the emergencies that new generations will have to face in the future. Based on these premises, we designed and validated a sustainable career guidance intervention for high school students. The participants $(N=75)$ were assigned to an experimental or a control group. All of the participants answered questions pre- and post-intervention to measure career adaptability, training, future investment, and wishes about the feature. The students from the sustainable career intervention group increased their post-intervention scores on control, curiosity, confidence, training, and future investment. They also indicated future wishes that take into more account attention to relationships and social challenges.
\end{abstract}

Keywords: career intervention; inclusion; sustainability

\section{Introduction}

The idea of the present and the near future involves high levels of ambiguity, change, and complexity. The principal threats and challenges with which young people, in particular, will have to confront are different, including socio-economic policies and inequalities, a super-diverse society, the role of technologies, and life on our planet [1,2]. As regards socio-economic policies, some authors (e.g., [1,3]) claim that, in the past few decades, there has been an ideological tendency, a neo-liberalistic view of the world, that emphasized the belief that an individual's wellbeing is connected to items, their purpose, and consumption [4]. Globalization has underlined the concept of transformation because of capital's free movement, with consequentially lowered production costs [5]. As a consequence, after some time, inequalities have escalated [6]. Therefore, it is easy to believe that our towns, cities, and regions will be more and more characterized by super-diversity. This term refers to a dynamic interaction of variables among a growing number of individuals who present multiple origins, who are transnationally related, socio-economically differentiated, and legally layered [7]. These individuals contribute to the development of complicated, unpredictable events [8]. All of this is also compounded by the technologies contributing to the worsening of working conditions for many people, increased wage disparities, the polarization of richness, and occupations [9].

Lastly, regarding the concepts of life on Earth, goods production and 'wellbeing' in general, they were connected to a view of the 'exploitation of resources' and strategies including the adoption of more natural resources than the available ones, since nations use more resources than ecosystems 
can generate, at the cost of others [10]. Humanity is proceeding in an unsustainable manner, draining the planet's finite natural resources faster than they are produced. In addition to making living circumstances more complex, this further raises impoverishment and inequality so much that it may threaten future generations' opportunities to survive and achieve their goals regarding progress [11]. This could happen even in the wealthiest nations that seem to have protected themselves from the danger of being excluded and impoverished. Younger people and human beings with disabilities, past migrations, and family unemployment are particularly in danger [12].

The neoliberalist socioeconomic perspective, along with adversities and complicated living situations in larger and larger groups of the population, promoted an ethic of disengagement towards the community, leading to individualization, which does not take into account the risks of exclusion and vulnerability [13]. The disappearance of a democratic 'socio-political community' within which citizens can support each other and share problems and successes increases competition among individuals rather than mutual solidarity, and this also contributes to feelings of distrust in the younger generations, as well as high levels of uncertainty associated with the future $[1,14]$.

Career practitioners increasingly recognize that their role in this context is to help people think about their personal and professional contribution to these global challenges, and to question in which work activities to engage, because they produce exchangeable goods or services that contribute to the construction of sustainable and inclusive social contexts [15]. As suggested by Guichard [16], this requires the design and implementation of interventions that vary considerably from the ones carried out nowadays in career guidance activities. Thus, we respond to this call by proposing a career intervention based on Sustainable Development, which is useful in activities to support the examination of adolescents' propensity to consider social challenges in their training and professional choices.

Some researchers suggested that adolescents who present constant worries and anticipate a gloomy future are more likely to exhibit negative emotions and problem behavior, like engaging in delinquency, substance use, and risky sexual behavior [17,18]. Furthermore, as suggested by Iovu, Hărăgus, and Roth [19], and by Ginevra et al. [20], the way in which adolescents construct their future can have severe and far-reaching effects on their future wellbeing and behavior and training investment, especially in higher education.

According to Eurostat data, Italy is near the bottom of the EU table for the number of young university graduates: less than one person out of six of working age has a degree in Italy, the second-worst figure in Europe after Romania. Eurostat data [21] on education levels in 2017 highlighted that Italy would negatively record graduates, with $13.7 \%$ of them being between 15 and 64 years of age.

This is a worrying situation in the current context. Training has become indispensable in order to train young people to design their futures in complex environments, where holistic visions and approaches need to be developed in order to attain the transition to a sustainable society and simultaneously call for a development marked by increased complexity. Education is, overall, considered to be an important contributor that promotes sustainability, as it enables us to train graduates who can understand and prevent global threats and to look for new, complex, and innovative solutions to these challenges, in order to ensure themselves and the future generations a society that can provide wellbeing and satisfaction [16,22,23].

Furthermore, given the demands and threats of the twenty-first century, it has become increasingly important to help young people to re-invest in their future, paying attention to their skills to deal with future challenges and unpredictable situations, through career adaptability, along with those skills which allow young people to find meaning for their future in this self-destroying reality [24,25]. Adolescents who feel more responsible for their future, and therefore invest more in its construction, tend to put more effort into learning, and achieve better grades than adolescents who think less about possibilities regarding their future in general, their future study and their careers [26]. 


\subsection{Life Design Approach to Inclusive and Sustainable Vocational Guidance Activities}

Given the dangers humanity is facing at the moment, particular attention has recently been paid to issues related to social justice, inclusion, decent work, and sustainable development [16]. As such, in career intervention actions characterized by inclusion and sustainability, it could be essential to stimulate youth to think less about the self and more about what could happen to other people, recognizing responsibility, commitment, and the possible mission that every individual would like to accomplish and carry out for his/her future. As Hooley et al. [1] also affirm, there is no career intervention without social solidarity and inclusion; without ensuring supports, protections, emergency lanes, and rescue systems; at least as concerns people who are less capable of taking part in competitions.

This process could be essential to stimulate young people involved in career intervention activities, in order to develop their career adaptability to be ready to cope with the changes and challenges that individuals encounter. As suggested by Johnston [27], the concept of career adaptability, in recent years, has frequently been noted as a resource that is necessary for successful career development, and responding positively to several challenges in the domains of career and work, and improved wellbeing. Savickas and Porfeli [28] highlight the relationship between career adaptability and adapting responses, which are the actual behaviors that help individuals to meet changing conditions, such as investment in the future and education [28]. Future investment has been found to be necessary for adolescents' knowledge [29]. However, we must operate not only on the young people's personal career lives, but rather all aspects of their lives, and also take into account the impact that individual life choices can have on the environment and people at the broader systemic level, not only in isolation, but integrated [30,31]. In this way, a sustainable development career may be designed for people, which is related to inclusive economic, social and environmental development, aiming to build a continuous process through all of the phases of career planning, applying a more comprehensive vision, looking at the local, the regional, and the global facets, showing the need of cooperation [32].

In doing this, it may be essential to develop abilities such as looking at the outside world, being curious, and imagining what may happen in the future, by keeping in mind that all of this could not be considered in terms of personal interests, passions, and capitals [12,33]. Besides this, it may be essential, to begin with the challenges that young people would like to face, and the abilities they would like to obtain and develop in order to help them manage these challenges. This would help minimize the risk of making the future mostly dependent on the past/present, and on several personal and contextual determinisms that can be inhibitory for possibilities and wishes [34,35]. By moving toward the future and thinking about the challenges young people would like face, attention and worries will shift to intentions, to desired perspectives, to the things that must be acquired and reinforced, to the circumstances that have to be encouraged and looked for, to the occasions to be identified with insatiable curiosity, and to goals chased with perseverance. These goals will have to be significant and meaningful to those who intend to follow them [13].

The desire to give a personal contribution can itself encourage investments in the future, even if the detected goals could still appear to be uncertain, temporary, not so realistic or smooth, and still likely to be modified [33]. More accurately, young people may perceive the importance of investing in training for the promotion of general cultural and civic values, to prepare for life and work in the context of social and cultural changes; for the development of personal and national identity, statehood, and cultural belonging; and for the development of responsibility for themselves, for others, for society, and for the environment [36].

Consequently, vocational guidance must be restored as a social form of support for individuals, and as a 'political' measure regarding public administrators [37]. Thereby, the 2030 Agenda values, adopted by every United Nations (UN) Member State, can be considered, and their encouragement to think about some of the events and complex situations that may happen in the future to the coming generations has to be acknowledged. Furthermore, as the UN recently asserted, COVID-19 is spreading human suffering, destabilizing the global economy, and upending the lives of billions of people 
around the globe. The pandemic is an unprecedented wake-up call, laying bare deep inequalities and exposing precisely the failures addressed in the 2030 Agenda for Sustainable Development and the Paris Agreement on climate change. Leveraging this crisis moment, when usual policies and social norms have been disrupted, bold steps can steer the world back on track towards the Sustainable Development Goals. This is the time for a change, for a profound systemic shift to a more sustainable economy that works for both people and the planet. The Sustainable Development Goals are vital for a recovery that leads to greener, more inclusive economies and healthier, more resilient societies.

Taking into consideration what was mentioned above, we think that the future may be more just if decisions and plans, including professional projects, and particularly those of teenagers, are less 'egocentric' and more directed to the choice of actions that enable them to accomplish their wellbeing. In addition, these activities allow young people to be motivated by less individualistic values, and to support the implementation of quality life contexts for everybody. In these contexts, only the utopia of inclusive, equitable, and sustainable development should be taken into account $[38,39]$. Vocational guidance has to preserve its original social task: social and ethical values, a focus on the situations of higher vulnerability, caring for people, and life contexts [16], thus strengthening-with inclusive and sustainable operations - the considerations already suggested in the Life Design (LD) approach.

\subsection{Purpose of the Study}

Vocational guidance and counseling services have been identified as indispensable tools for the assistance of secondary school students in changing for life actualization, leading to sustainable development [40]. Despite this, it seems that training for young high school students on vocational guidance and sustainability does not appear to be present in the literature. From this perspective, in the current study, we produced a career intervention activity called 'Looking to the future and the university inclusive and sustainable way'. This activity is designed to inspire young people to reflect on the future, taking into account the threats that our society is facing, and thus considering which study course to undertake and what professional improvement to provide in order to make their contribution, by the year 2030, the the attainment of at least some of the 17 goals that the UN proposed for the entire planet. In order to assess the efficacy of the career intervention, we examined the post-intervention change's statistical significance in several key career development variables. We have examined the propensity to identify desires for the future that take into account not only personal goals but also the social challenges encountered today, with a focus on sustainable and equal development and career adaptability, which are essential to the design and management of a professional future [28], and investmentment in the future and education [41]. Furthermore, we measured the indicators of the intervention's social validity. As promoted in the social validity literature, these indicators included participants' perceived satisfaction with the intervention, and its usefulness for career planning, self-reflection, and investment in the future and education [33].

Following the career intervention, we expected that-in contrast to a more traditional vocational guidance activity-the sustainable career intervention group would report greater post-test levels of inclusive and sustainability wishes to undertake for their future, career adaptability, and future and training investment. We also expected that the experimental group would be satisfied with the career intervention and evaluate it as helpful, practical, and essential for the consideration of particular aspects of their career development. In conclusion, we examined the comparative effectiveness of the career intervention and the social validity of its use for high school students.

\section{Method}

\subsection{Participants}

The participants were 75 high-school students with a average age of 17.21 years $(S D=0.62)$. Every participant attended five distinct classes of public high schools in the northeast part of Italy. 
In total, 43 students ( $88 \%$ ) from three different courses of three public schools accepted to join the 'Looking to the future and to the university in an inclusive and sustainable way' career intervention (experimental group), and 32 students (96\%) from two classes of another public school aggreed to carry out a vocational guidance program, and took part (control group). The experimental and control groups contained $2 \%$ and $1 \%$ first-generation immigrants from North Africa and Eastern Europe, respectively, and the remaining participants were native Italian.

A sample size calculation confirmed that this is a sufficient number of participants. Based on the ability to detect a medium effect size or a larger clinical effect (Cohen's $d>0.45$; [42]), and tested at a conventional power of (1-beta) 0.50 and an alpha of 0.05 (one-tailed testing), a total number of 70 participants was required.

No significant gender differences were detected between the intervention group and the control group: $\chi^{2}(1)=0.135, p=0.447$; nor were any age differences: $t(73)=1.356, p=0.179$.

\subsection{Measures}

Wishes about the future. Considering past studies [41,43] that suggest the stimulation of young people's reflections on their wishes about the future, the participants were invited to answer this question: "About my future, what I desire most is...". The answers to this question were examined taking into consideration these categories, referring to the Life Design approach [41,44]: attention to self and personal goals, attention to relationships, and social challenges. The participants answered this question at the beginning and the end of the intervention.

Career adaptability. We used the Career Adapt-Abilities Scale (CAAS [28]). The CAAS includes 24 items set on a 5-point Likert-type scale ranging from 1 (not strong) to 5 (strongest). The 24 items combine to yield a total career adaptability score. The items also form four separate subscales that measure the career adaptability resources of concern, control, curiosity, and confidence. For the current study, we used the Italian validated version of the CAAS for middle-school students [45]. The Cronbach's alphas for the four subscales in the present study were 0.78 (concern), 0.71 (control), 0.75 (curiosity), and 0.86 (confidence).

Investment in the future. An investment in the future is the inclination to feel responsible for creating a future personal life. In order to measure it, we used the 4-item Locus of Control subscale of the Ideas and Attitudes on School-Career Future-High School Version [46]. The participants indicated, on a 5-point scale, how much each statement depicted their usual opinion and behavior $(1=$ Does not describe me at all; $5=$ Describes me very well). The scale uses reverse scoring, which means that a lower score corresponds to a higher investment level in the future. The sample items include statements like "It is useless to try to think about my future ... a lot will depend on the case". In the present study, the alpha was 0.72 for the sustainable career intervention group, and 0.70 for the more traditional group.

Training investment. In order to determine future training investment, we used Gati et al.'s [47] Career and Education Decision Status Scale. The participants were asked to answer to one question on a 6-point Likert-type scale ( 1 = Not at all decided; 6 = Very decided): "About what to do after high school, which of these statements best describes your current situation?". In a prior study of Nota, Santilli, and Soresi [48] the Cronbach's alpha of these items was 0.66 , and the were positive correlations with the level of career adaptability and hope students had about their future.

Social validity. To examine the social validity of the 'Looking to the future and the university in an inclusive and sustainable way' intervention, we created two items that were designed for use post-test to determine the experimental group participants' global satisfaction with the intervention, and the perceived usefulness and significance of the training and actions based, on the research by Ginevra et al. [49]. The participants responded to each item using a 5-point Likert-type scale, ranging from 1 (not satisfied) to 5 (extremely satisfied). 


\section{3. 'Looking to the Future and the University in an Inclusive and Sustainable Way' Career Intervention}

For the experimental group, we developed and carried out a group career intervention for secondary school students, with and without disabilities and/or learning difficulties, in diversified classes. The intervention title is 'Looking to the future and to the university in an inclusive way'. The goal was to support investment in university education. It included five didactic units, of two hours each at once, weekly, for 5 weeks in total. Vocational guidance practitioners-with a postmaster diploma certification in career counseling and vocational guidance-led the training sections.

In the first Didactic Unit, there was an explanation regarding the meaning of career guidance and the kind of assistance that it gives to people. Later, as proposed by [24], there was a discussion concerning the five areas of crucial importance for humanity and the planet identified by the UN (People, Planet, Prosperity, Peace, and Partnership). In this way, students can be prepared to address the issues that threaten sustainability on our planet. Successively, students were asked to analyze these issues in connection with their hopes and worries for the future.

In the second didactic unit, in order to develop a global perspective and develop students as global citizens exposed to a range of views on globalization [50], the 17 Sustainable Development Goals set by the UN were introduced and explained. According to them, the students were invited to enumerate the more interesting objectives (at least a couple) and explain why they were chosen. During this meeting, there was also a discussion about the significance of education and the future's determination. The teenagers were asked to think about the benefits that these resources can convey to their tomorrow. They were also invited to reflect on how the above-mentioned resources may be connected to the UN objectives to develop skills, points of view, and values that encourage sustainable living [51]. Throughout the third and fourth encounters, the students were encouraged to reflect on their possible future missions, considering social emergencies and objectives. The possible mission can be considered to be future and imaginable activities and occupations through which people, with other professionals' help, try to meet one of the most worrying challenges for their future [33].

In the last didactic unit, teenagers were supported in the detection of jobs and professions that are connected to their missions, and the potential formation processes that can facilitate them to obtain the appropriate knowledge and skills to perform them. The various and broad academic fields were analyzed, without examining specific degree courses in line with this. This encouraged the adolescents to think about the purpose of education to accomplish their missions, and the contribution that instruction and training could give concerning the pursuit of the objectives, and the management of the emergencies detected [49].

\subsection{More Traditional Vocational Guidance Activity}

During the same period in which the guidance intervention group completed the 'Looking to the future and to the university in an inclusive way', the more traditional group was led in the classroom without the vocational guidance practitioners' active intervention. The intervention was conducted in the class during the hours dedicated to vocational guidance activities, which Italian high schools reserve for students who are about to choose their future university and/or work, as requested by the Italian school programs [52]. The more traditional group was given the professional vocational guidance carried out in different high schools in the northeast part of Italy, from whence the guidance intervention group was drawn. The adolescents in the more traditional group answered, in paper and pencil, on the measures of their interests, values, and study motivation. In accordance with their answers, the adolescents obtained an individualized report detailing their principal strength, which is useful to plan their future and decide on their education or work. In the first two meetings of two hours each, the students filled out the questionnaire, and after seven days, the individualized report was delivered in a sealed envelope. Said reports were examined with the adolescents in groups, and a range of information about university training education and employment opportunities were also presented. These activities took approximately 2 hours, and overall, the more traditional group took six hours in three sections. 


\subsection{Data Analysis}

The intervention's effectiveness was valued by carrying out repeated-measures analyses of variance over time as a treatment condition function. The independent variable was the treatment condition (intervention vs. control group). The pre-post measurement was the repeated measurement factor time [53]. The effect size was assessed using the partial eta squared ( $\eta 2 p)$, which evaluates the percentage of variance explained by each variable. Conventionally, the threshold values for the index $\eta 2 p$ are $0.01,0.06$, and 0.14 , which indicate, respectively, a small, moderate, and large effect size [54].

\section{Results}

The coding of responses to the question "About my future what I most desire is ... " (wishes about the future) will be detailed below.

The first and second authors individually analyzed the answers to the question. The percentage of agreement between the two coders was over $98 \%$ for all of the categories.

\subsection{Preliminary Analyses}

Table 1 shows the correlations among the study variables in the pre- and post-test. Table 2 shows the means and standard deviations for the participants in the control and sustainable career intervention group for the pre-test and post-test.

Table 1. Correlations among the study variables at pre- and post-test.

\begin{tabular}{lccccccc}
\hline \multicolumn{1}{c}{ Measure } & $\mathbf{1}$ & $\mathbf{2}$ & $\mathbf{3}$ & $\mathbf{4}$ & $\mathbf{5}$ & $\mathbf{6}$ & $\mathbf{7}$ \\
\hline 1. Concern & - & $0.528^{* *}$ & $0.565^{* *}$ & $0.526^{* *}$ & -0.117 & 0.219 & -0.207 \\
2. Control & $0.515^{* *}$ & - & $0.538^{* *}$ & $0.707^{* *}$ & -0.032 & 0.086 & 0.008 \\
3. Curiosity & $0.452^{* *}$ & $0.547^{* *}$ & - & $0.614^{* *}$ & 0.119 & 0.079 & 0.025 \\
4. Confidence & $0.533^{* *}$ & $0.576^{* *}$ & $0.560^{* *}$ & - & 0.051 & 0.094 & 0.043 \\
5. Investment in the future & $-0.415^{* *}$ & $-0.239 *$ & -0.050 & -0.033 & - & $-0.392 *$ & -0.144 \\
6. Training Investment & 0.185 & 0.033 & 0.073 & -0.075 & $-0.271^{*}$ & - & -0.034 \\
7. Wishes about the future & 0.048 & 0.133 & 0.036 & 0.136 & 0.000 & -0.085 & - \\
\hline
\end{tabular}

Note: the intercorrelations for the pre-test $(n=75)$ are presented below the diagonal, and the intercorrelations for post-test $(\mathrm{n}=75)$ are presented above the diagonal; ${ }^{*} p<0.05 ;{ }^{* *} p<0.01$.

Table 2. Means and standard deviations of the experimental and control group at pre- and post-test.

\begin{tabular}{|c|c|c|c|c|c|c|c|c|c|c|c|c|}
\hline \multirow[b]{3}{*}{ Measure } & \multicolumn{4}{|c|}{ Experimental Group } & \multicolumn{4}{|c|}{ Control Group } & \multicolumn{4}{|c|}{ Total } \\
\hline & \multicolumn{2}{|c|}{ Pre } & \multicolumn{2}{|c|}{ Post } & \multicolumn{2}{|c|}{ Pre } & \multicolumn{2}{|c|}{ Post } & \multicolumn{2}{|c|}{ Pre } & \multicolumn{2}{|c|}{ Post } \\
\hline & $M$ & $S D$ & $M$ & $S D$ & $M$ & $S D$ & $M$ & $S D$ & $M$ & $S D$ & $M$ & $S D$ \\
\hline 1. Concern & 19.70 & 4.30 & 21.33 & 4.26 & 20.34 & 3.59 & 20.63 & 3.77 & 19.99 & 3.98 & 21.01 & 4.04 \\
\hline 2. Control & 22.80 & 4.13 & 23.88 & 3.76 & 23.63 & 2.85 & 22.50 & 3.99 & 23.17 & 3.62 & 23.26 & 3.90 \\
\hline 3. Curiosity & 21.00 & 3.85 & 22.20 & 4.16 & 22.09 & 2.79 & 21.03 & 3.47 & 21.49 & 3.44 & 21.68 & 3.89 \\
\hline 4. Confidence & 22.15 & 4.39 & 23.13 & 3.49 & 23.28 & 3.48 & 21.75 & 3.93 & 22.65 & 4.03 & 22.51 & 3.73 \\
\hline 5. Investment in the future & 8.75 & 2.77 & 8.18 & 2.09 & 8.03 & 2.24 & 9.34 & 2.56 & 8.43 & 2.56 & 8.69 & 2.37 \\
\hline 6. Training Investment & 1.23 & 1.25 & 1.78 & 1.23 & 1.28 & 1.08 & 0.97 & 1.06 & 1.25 & 1.17 & 1.42 & 1.22 \\
\hline 7. Wishes about the future & 0.25 & 0.44 & 0.53 & 0.85 & 0.22 & 0.42 & 0.28 & 0.52 & 0.24 & 0.43 & 0.42 & 0.73 \\
\hline
\end{tabular}

A MANOVA was conducted in order to determine if there were significant differences between the treatment group condition at the time of the pre-test for any of the dependent variables (concern, control, curiosity, confidence, future investment, training investment, wishes about the future).

The MANOVA revealed no significant differences between the two groups (career intervention vs. more traditional group) (Wilks's $\lambda=0.872, \mathrm{~F}(8 ; 65), p=0.316$ ). 


\subsection{Pre and Post-Rest Comparisons}

In order to assess the differences between the two group treatment conditions and the time on any of the dependent variables (concern, control, curiosity, confidence, future investment, training investment, wishes about the future), different repeated-measure MANOVAs were conducted (see Table 2).

Regarding career adaptability, a significant interaction was yielded for the treatment condition $\mathrm{x}$ time condition, Wilks's $\lambda=0.129(\mathrm{~F}(4 ; 69)=2.545 ; p=0.047) ; \eta^{2} \mathrm{p}=0.129$. Table 2 shows the mean values obtained. At the univariate level, the following variables revealed significant differences: Control, $\mathrm{F}(1 ; 72)=6.219, p=0.015, \eta^{2} \mathrm{p}=0.080$, Curiosity, $\mathrm{F}(1 ; 72)=6.701, p=0.012, \eta^{2} \mathrm{p}=0.085$, and Confidence, $\mathrm{F}(1 ; 72)=8.232, p=0.005, \eta^{2} \mathrm{p}=0.103$. The analysis revealed that the students in the sustainable career intervention group showed more concern, curiosity, and confidence than the more traditional intervention group. Table 2 reports the means and standard deviations of the sustainable career intervention and the more traditional group at pre-test and post-test.

Regarding future investment, a significant interaction was yielded for treatment condition $\mathrm{x}$ time condition, Wilks's $\lambda=0.845(\mathrm{~F}(1 ; 73)=13.392 ; p=0.001)$ eta $^{2}=0.155$. Specifically, the average levels of indecision towards the future were lower in the post-test participants who took part in the sustainable career intervention than the average levels reported by the control group participants.

Regarding training investment, a significant interaction was yielded for treatment condition $\mathrm{x}$ time condition, Wilks's $\lambda=0.898(\mathrm{~F}(1 ; 73)=7.928 ; p=0.006)$; eta $^{2}=0.102$. Specifically, the average levels of training investment were higher in the post-test participants who took part in the sustainable career intervention than the average levels reported by the control group participants.

Finally, regarding the categories used in the qualitative answers related to the future, a significant interaction was yielded for treatment condition $x$ time condition, Wilks's $\lambda=0.925$ (F $(2 ; 73)=3.364$; $p=0.030$ ). Specifically, the sustainable career intervention group reported, at the post-test, more categories related to their attention to relationships and to others, and to describe their wishes about the future, than the participants of the control group.

Participants' Evaluation of the Career Intervention. Lastly, we assessed the social validity of the vocational guidance intervention. Overall, the students assessed the vocational guidance intervention as being essential to their reflection upon specific dimensions, and appropriate to handle future professional plans and transitions. Specifically, $14 \%$ stated that they were delighted with the entire program, $45 \%$ stated that they were satisfied, $36 \%$ stated that they were neutral, $3 \%$ stated that they were a little satisfied, and 2\% stated that they were not satisfied at all satisfied; $29 \%$ indicated that they were delighted to be a part of the sustainable career intervention, $40 \%$ indicated that they were satisfied, $20 \%$ indicated that they were neutral, $6 \%$ indicated that they were a little satisfied, and $5 \%$ indicated that they were not satisfied at all.

\section{Discussion}

The world is becoming increasingly complex and uncertain, and is characterized by mega-trends such as globalization, the mixture of cultures, and the growth of economies. In addition to these trends, humanity is altering the planet's climate, animals, and landscapes in unprecedented ways, and is threatening Earth's life. Given these global developments, students and youth have an increasing demand for education beyond teaching knowledge and skills just to find a job. Above all, students need new perspectives to understand the rapidly changing world they live in [55]. Furthermore, youth need to participate in this world. Many of them also want to help reduce poverty, protect the environment, and create inclusive societies [55]. In order to realize this ambition, a new approach to career intervention which takes this into account is needed. This research proposed a trajectory in this direction with a career intervention-'Looking to the future and the university in an inclusive and sustainable way'-inspired by the LD approach, aiming to educate students as global citizens for sustainable development $[16,56]$. The program aims to engage youth to reflect about the future and address the threats that our society is facing, starting with the challenges that young people want to face, and the skills they want to acquire and develop in order to contribute to facing them. It also tries to 
motivate them to take more responsibility for their futures, and stresses the importance of investing in higher education to be prepared for life and work in the context of social and cultural changes, and for the development of responsibility for themselves, for others, for society, and for the environment.

In the present paper, the career intervention program was initially validated. Our findings indicated that students in the 'Looking to the future and the university in an inclusive and sustainable way' career intervention group showed higher levels of career adaptability-specifically of concern, control, confidence-and greater levels of investment in higher education than did those in the more traditional group. Moreover, the students from the inclusive and sustainable career intervention group expressed future wishes that include some crucial aspects of the LD approach, i.e., attention to the self, personal goals, and relationships and social challenges. The results appear to be promising, considering the partial eta squared values between 0.10 and 0.15 , which are regarded as the medium. Overall, these results highlighted the vocational guidance's role in enhancing sustainable development among secondary school students [40].

Regarding career adaptability, which had the highest levels of control, the career intervention supports young people to find their voices and identify the role they can play in building a quality future for themselves and others. On the other hand, the young people may have experienced the possibility of having an active role in becoming critical and creative thinkers, and in co-designing their future wishes and learning what is necessary for the world in which they now live, and for the futures they will need to define for themselves and future generation. As regards curiosity, our results show significant differences, and this, according to us, may be because the intervention put the young people in front of questions and challenges that did not come from the doubts they had. On the contrary, it required them to explore something that they recognized as being new to focus their attention on. Encouraging curiosity increases the motivation to look for information [57], and to concentrate on the essential details of higher education and university in order to detect jobs and lines of employment connected to their missions, and possible training processes that can assist them in the acquisition of knowledge and abilities that are useful to accomplish them [58,59].

Regarding confidence, working backward by moving into the future, thinking about the challenges that young people would like to face, their attention and worries may have become intentions, possible missions, with the detection of activities they felt they were able to do. This may have prompted a feeling of self-efficacy to successfully execute the actions needed in order to achieve their career goal, and then - as suggested by Hirshi, Hermann, and Keller [60] —an increase in problem-solving skills and a feeling of being efficacious. As Koen et al. [61] suggested, career confidence is connected to the employment of an exploratory approach. As regards this concern, our intervention did not highlight significant results. It may be necessary, for future interventions, to try to make the challenges face even closer to young people's lives, so that they can be encouraged to consider future scenarios more closely, to examine them more clearly, and not to feel distant from them.

This intervention is associated with increased investments in higher education. In line with the results by Duffy [62] and Negru-Subtirica [63], inviting the students to feel more responsible for their future, and therefore to invest more in its construction, can enable them to put more effort into higher education and future planning, since they take into consideration the advantages associated to it. As a consequence, we can say that the intervention helped young people to consider higher education as a means that, through democratic values and multidimensional learning, can be characterized as a way to undertake future challenges and sustainable development, as suggested by Pucciarelli and Kaplan [64]. Yáñez, Uruburu, Moreno and Lumbreras [65], and Rossier et al. [35], examined the value that Universities acquired in training and promoting future experts by instructing them, realizing new tools with which to face new challenges in modern society thanks to their organizations and research resources, and sharing their knowledge to add inclusive and sustainable value to companies and societies.

The inclusive and sustainable career intervention group students also underlined their future wishes that consider some critical aspects of the LD approach, i.e., attention on self and personal goals, attention to relationships, and social challenges. This result may be due to the use of reflection, 
which, as is also supported by Cohen-Scali and Pouyaud [66], brings a greater recognition of young people as being sociopolitically active participants in their futures, and the futures of their communities. During the career training, there was an attempt to develop consciousness in young people. This consciousness, as supported by Roy, Raver, Masucci, and DeJoseph [67], brings young people to understand how to learn to analyze their social conditions, and how to act to change them.

Overall, our results are in line with Arulmani [68], who stated the importance of the development of career intervention with sensitivity to the 'other', asking the individual to define the purpose and outcomes of his/her engagement with work, and with the importance given by Guichard [16] to the reflections on the construction of futures that take into consideration the planet we live on. This principle points out that the way in which an individual engages with work should be a reflection of 'right living', aiming to promote a sustainable career design, in harmony within oneself, the community, and the environment; this could lead toward a situation wherein the realization of an individual's potential would support, rather than exploit, the environment in which the career is practiced. Moreover, our results indicate that it is possible to create a career intervention based on the LD approach, focused on career adaptability. As a consequence, it is also possible to improve a series of unique resources to manage developmental tasks to be prepared for sustainable future careers, and to face the challenges that we are going through. As a consequence, occupations are considered to be dynamic interactions between the garnering of personal gain and the services that people render to society at large, and-more generally-this leads to life designs in which one's duty is to use one's achievements as a platform of service to others $[68,69]$.

\subsection{Implications for Practice}

The work carried out has proved that it is possible to realize inclusive and sustainable career interventions in large groups in school contexts, which are able to encourage young people to look at the external reality, to what will happen in the future, supporting them to work backward, starting from the challenges they would like to face, and then reflecting on the abilities that they wish to obtain and develop in order to reach their goals. This should be done by moving toward the future, from the threats that humanity and the Earth are suffering, thinking about the challenges that young people would like to face. The latter will outline their desires, the things they have to learn and strengthen, the conditions to be encouraged and looked for, the occasions to be discovered with insatiable curiosity, and the goals to be pursued with perseverance. These goals will have to be relevant and meaningful to those who intend to follow them, and encourage them to move toward them already in the present, anticipating the future in ecological-behavioral terms. This will combine private and public spheres,

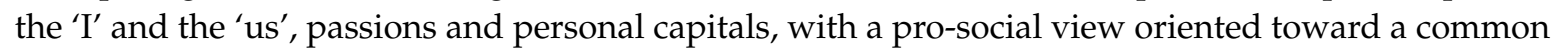
good. This also facilitates the dissemination of a new culture of vocational guidance that considers individuals both as being subject to and actors upon the material and social world, understanding that their actions have impacts now and in the future, and contributing to the improvement of places and relationships that seem imperative, given the conditions of this era we find ourselves.

\subsection{Limitations and Future Research Directions}

Although some encouraging results emerged, our study presents some limitations. Firstly, the findings and reflections described concern the northeastern Italian school context. Hopefully, future research will involve participants from other Italian regions in order to verify the generalizability of the analyses reported in this study. Future research involving career interventions regarding the assessment of 'Looking to the future and the university in an inclusive and sustainable way' should include students of different ages.

Moreover, it must also be remembered that the satisfactory assessment of training efficacy should not be limited to recording changes that happen just a few weeks after the program's conclusion. Future research should also include 6- and 12-month follow-ups to control for whether students preserve and generalize the developments thanks to the intervention. It would be essential to repeat the study using a tool that measures explicitly the high school students' sustainability investment. 
Future research could also consider the impact that this career intervention may have on other variables linked to the LD approach, such as the narrations about the future of young adolescents.

Author Contributions: Conceptualization, S.S. (Sara Santilli); Formal Analysis: S.S. (Sara Santilli); Methodology, M.C.G. and I.d.M.; Writing review and editing: S.S. (Sara Santilli), and L.N.; Supervision, S.S. (Salvatore Soresi). All authors have read and agreed to the published version of the manuscript.

Funding: This research received no external funding.

Conflicts of Interest: The authors declare no conflict of interest.

\section{References}

1. Hooley, T.; Sultana, R.G.; Thomsen, R. (Eds.) Career Guidance for Social Justice: Contesting Neoliberalism; Routledge: Abingdon, UK, 2018.

2. Nota, L.; Di Maggi, I.; Santilli, S. Verso un orientamento inclusivo e sostenibile [Tward an inclusive e sustainable vcatinal guidance]. Riv. Sci. Educ. 2019, 2, 221-233.

3. Nota, L.; Soresi, S. Counseling and Coaching in Times of Crisis and Transitions: From Research to Practice; Routledge: Abingdon, UK, 2018.

4. Watkins, P.C.; McLaughlin, T.; Parker, J.P. Gratitude and subjective wellbeing: Cultivating gratitude for a harvest of happiness. In Scientific Concepts behind Happiness, Kindness, and Empathy in Contemporary Society; Silton, N.R., Ed.; IGI Global: Hershey, PA, USA, 2019; pp. 20-42.

5. Chomsky, N.; Polychroniou, C.J. Optimism over Despair; Penguin: London, UK, 2017.

6. Milanovic, B. Global Inequality: A New Approach for the Age of Globalization; Harvard University Press: Cambridge, MA, USA, 2016.

7. Vertovec, S. Talking around super-diversity. Ethn. Racial Stud. 2019, 42, 125-139. [CrossRef]

8. Nota, L.; Rossier, J. Handbook of Life Design: From Practice to Theory and From Theory to Practice; Hogrefe: Göttingen, Germany, 2015.

9. Ford, M. Rise of the Robots: Technology and the Threat of a Jobless Future; Basic Books: New York, NY, USA, 2015.

10. Walls, L.D. Emerson's Life in Science: The Culture of Truth; Cornell University Press: New York, NY, USA, 2018.

11. Hallegatte, S.; Fay, M.; Barbier, E.B. Poverty and climate change: Introduction. Environ. Dev. Econ. 2018, 23, 217-233. [CrossRef]

12. Cohen-Scali, V.; Pouyaud, J.; Podgórny, M.; Drabik-Podgorna, V.; Aisenson, G.; Bernaud, J.L.; Guichard, J. Interventions in Career Design and Education: Transformation for Sustainable Development and Decent Work; Springer: Paris, France, 2018.

13. Down, B.; Smyth, J.; Robinson, J. Rethinking School-to-Work Transitions in Australia: Young People Have Something to Say; Springer: Dordrecht, The Netherland, 2018.

14. Alietti, A.; Agustoni, A. Integrazione, Casa e Immigrazione. Esperienze e Prospettive in Europa, Italia e Lombardia (Integration, Housing and Immigration. Experiences and Perspectives in Europe, Italy and Lombardy); Fondazione Ismu Regione Lombardia: Milano, Italy, 2013.

15. Pouyaud, J.; Guichard, J. A twenty-first century challenge: How to lead an active life whilst contributing sustainable and equitable development. In Career Guidance and Social Justice in a Neoliberal World; Hooley, W.T., Sultana, R.G., Thomsen, R., Eds.; Routledge: Abingdon, UK, 2017.

16. Guichard, J. Life Design Interventions and the Issue of Work. In Interventions in Career Design and Education: Transformation for Sustainable Development and Decent Work; Cohen-Scali, V., Pouyaud, J.P., Drabik-Podgorna, M., Aisenson, G., Bernaud, J.L., Guichard, J.V., Eds.; Springer: Paris, France, 2018; pp. 15-28.

17. Milot Travers, A.S.; Mahalik, J.R. Positive youth development as a protective factor for adolescents at risk for depression and alcohol use. Appl. Dev. Sci. 2019, 1-10. [CrossRef]

18. Sipsma, H.L.; Ickovics, J.R.; Lin, H.; Kershaw, T.S. The impact of future expectations on adolescent sexual risk behavior. J. Youth Adolesc. 2015, 44, 170-183. [CrossRef] [PubMed]

19. Iovu, M.B.; Hărăgus, P.T.; Roth, M. Constructing future expectations in adolescence: Relation to individual characteristics and ecological assets in family and friends. Int. J. Adolesc. Youth 2018, 23, 1-10. [CrossRef]

20. Ginevra, M.C.; Magnano, P.; Lodi, E.; Annovazzi, C.; Camussi, E.; Patrizi, P.; Nota, L. The role of career adaptability and courage on life satisfaction in adolescence. J. Adolesc. 2018, 62, 1-8. [CrossRef] 
21. Eurostat. The Education and Training Monitor; Publications Office of the European Union: Luxembourg, 2018. [CrossRef]

22. Karatzoglou, B. An in-depth literature review of the evolving roles and contributions of universities to Education for Sustainable Development. J. Clean. Prod. 2012, 49, 44-53. [CrossRef]

23. Peterson, P.M.; Helms, R.M. Internationalization revisited. In The Forefront of International Higher Education; Maldonado-Maldonado, A., Bassett, R.M., Eds.; Springer: Dordrecht, The Netherland, 2014; pp. 101-111.

24. Handa, N. Education for Sustainability through Internationalisation: Transnational Knowledge Exchange and Global Citizenship; Springer: New York, NY, USA, 2018.

25. Husman, J.; Brem, S.K.; Banegas, S.; Duchrow, D.W.; Haque, S. Learning and future time perspective: The promise of the future-rewarding in the present. In Time Perspective Theory; Review, Research and Application; Stolarski, M., Fieulaine, N., van Beek, W., Eds.; Springer: New York, NY, USA, 2015; pp. 131-141.

26. Taber, K.S. Revisiting the chemistry triplet: Drawing upon the nature of chemical knowledge and the psychology of learning to inform chemistry education. Chem. Educ. Res. Pract. 2013, 14, 156-168. [CrossRef]

27. Johnston, C.S. A systematic review of the career adaptability literature and future outlook. J. Career Assess. 2018, 26, 3-30. [CrossRef]

28. Savickas, M.L.; Porfeli, E.J. Career Adapt-Abilities Scale: Construction, reliability, and measurement equivalence across 13 countries. J. Vocat. Behav. 2012, 80, 661-673. [CrossRef]

29. Andre, L.; van Vianen, A.E.; Peetsma, T.T.; Oort, F.J. Motivational power of future time perspective: Meta-analyses in education, work, and health. PLoS ONE 2018, 13, e0190492. [CrossRef]

30. Hartung, P.J. Life Design: A Paradigm for Innovating Career Counselling in Global Context. In Handbook of Innovative Career Counselling; Maree, J.G., Ed.; Springer: Cham, Switzerland, 2019; pp. 3-18.

31. Kenny, M.E.; Blustein, D.L.; Liang, B.; Klein, T.; Etchie, Q. Applying the psychology of working theory for transformative career education. J. Career Dev. 2019, 46, 623-636. [CrossRef]

32. Kimaryo, J. Strategies for Improving Competence Based Education in Tanzania: Experiences, Insight and Possibility. 2011. Available online: https://www.doria.fi/bitstream/handle/10024/67481/kimaryo_lydia.pdf? (accessed on 20 October 2020).

33. Soresi, S.; Nota, L.; Santilli, S. Il Contributo Dell'Orientamento e del Counselling All'Agenda 2030; CLEUP: Padova, Italy, 2019.

34. Hooley, T.; Sultana, R.G.; Thomsen, R. (Eds.) Career Guidance for Emancipation: Reclaiming Justice for the Multitude; Routledge: Abingdon, UK, 2019.

35. Rossier, J.; Aisenson, G.; Chabra, M.; Cohen-Scali, V.; Di Fabio, A.; Heslon, C.; San Antonio, D.M. Lifelong Learning, Counseling, and Life-Designing to promote Careers for the Future. 2019. Available online: https://recherche.uco.fr/publication/ID-UCO-4192 (accessed on 31 May 2019).

36. Beka, A. The Impact of Games in Understanding Mathematical Concepts to Preschool Children. J. Educ. Soc. Res. 2017, 7, 187-194. [CrossRef]

37. Fouad, N.A.; Kozlowski, M.B. Turning Around to Look Ahead: Views of Vocational Psychology in 2001 and 2019. J. Career Assess. 2019, 27, 375-390. [CrossRef]

38. Giovannini, E. L'Utopia Sostenibile (The Sustainable Utopia); Laterza: Bari, Italy, 2018.

39. Santilli, S.; Ginevra, M.C.; Nota, L.; Soresi, S. Decent work and social inclusion for people with disability and vulnerability: From the soft skills to the involvement of the context. In Interventions in Career Design and Education; Cohen-Scali, V., Pouyaud, J., Podgórny, M., Drabik-Podgórna, V., Aisenson, G., Bernaud, J.-L., Abdou Moumoula, I., Guichard, J., Eds.; Springer: New York, NY, USA, 2018; pp. 303-313.

40. Anyamene, A.; Ngwakwe, C.C. The Role of Vocational Guidance and Counselling in Enhancing Sustainable Development Among Secondary School Students in Nigeria. J. Guid. 2020, 4, 24-34.

41. Santilli, S.; Marcionetti, J.; Rochat, S.; Rossier, J.; Nota, L. Career adaptability, hope, optimism, and life satisfaction in Italian and Swiss adolescents. J. Career Dev. 2017, 44, 62-76. [CrossRef]

42. Lipsey, M.W.; Wilson, D.B. The efficacy of psychological, educational, and behavioral treatment: Confirmation from meta-analysis. Am. Psychol. 1993, 48, 1181. [CrossRef]

43. Hartung, P.J. Life design in childhood: Antecedents and advancement. In Handbook of the Life Design Paradigm: From Practice to Theory, from Theory to Practice; Nota, L., Rossier, J., Eds.; Hogrefe Publishing: Göttingen, Germany, 2015; pp. 89-102.

44. Savickas, M.L.; Nota, L.; Rossier, J.; Dauwalder, J.P.; Duarte, M.E.; Guichard, J.; Van Vianen, A.E. Life designing: A paradigm for career construction in the 21st century. J. Vocat. Behav. 2009, 75, 239-250. [CrossRef] 
45. Di Maggio, I.; Ginevra, M.C.; Nota, L.; Ferrari, L.; Soresi, S. Career Adapt-Abilities Scale-Italian Form: Psychometri properties with Italian preadolescents. J. Vocat. Behav. 2015, 91, 46-53. [CrossRef]

46. Soresi, S.; Nota, L. La Facilitazione Dell'Integrazione Scolastica; Erip: Pordenone, Italy, 2001.

47. Gati, I.; Gadassi, R.; Saka, N.; Hadadi, Y.; Ansenberg, N.; Friedmann, R.; Asulin-Peretz, L. Emotional and personality-related aspects of career decision-making difficulties: Facets of career indecisiveness. J. Career Assess. 2011, 19, 3-20. [CrossRef]

48. Nota, L.; Santilli, S.; Soresi, S. A life-design-based online career intervention for early adolescents: Description and initial analysis. Career Dev. Q. 2016, 64, 4-19. [CrossRef]

49. Ginevra, M.C.; Santilli, S.; Camussi, E.; Magnano, P.; Capozza, D.; Nota, L. The Italian adaptation of courage measure. Int. J. Educ. Vocat. Guid. 2019, 20,457-475. [CrossRef]

50. Zeichner, K. Rethinking the connections between campus courses and field experiences in college-and university-based teacher education. J. Teach. Educ. 2010, 61, 89-99. [CrossRef]

51. Bullivant, A. Global learning: A historical overview. In Global Learning and Sustainable Development; Gadsby, $\mathrm{H}$., Bullivant, A., Eds.; Routledge: Abingdon, UK, 2010; pp. 18-36.

52. MIUR. Linee Guida Nazionali per L'Orientamento Permanente (National Guidelines for Lifelong Guidance); Miur: Roma, Italy, 2014; Available online: http://www.istruzione.it/allegati/2014/prot4232_14.pdf (accessed on 30 June 2019).

53. O'Brien, R.G.; Kaiser, M.K. MANOVA method for analyzing repeated measures designs: An extensive primer. Psychol. Bull. 1985, 97, 316-333. [CrossRef] [PubMed]

54. Green, S.B.; Salkind, N.J. Using SPSS for Windows and Macintosh: Analyzing and Understanding Data, 3rd ed.; Prentice Hall: Upper Saddle River, NJ, USA, 2003.

55. Hunter, M.A.; Aprill, A.; Hill, A.; Emery, S. Education, Arts and Sustainability: Emerging Practice for a Changing World; Springer: Singapore, 2018.

56. Nota, L.; Soresi, S. Career Counselling and Vocational Designing for an Inclusive and Sustainable Future; Springer: New York, NY, USA, in press.

57. Kashdan, T.B.; Silvia, P.J. Curiosity and interest: The benefits of thriving on novelty and challenge. In Oxford Handbook of Positive Psychology; Snyder, C.R., Lopez, S.J., Eds.; Oxford Library of Psychology: New York, NY, USA, 2009; pp. 367-374.

58. Ginevra, M.C.; Nota, L. 'Journey in the world of professions and woek': A career intervention for children. J. Posit. Psychol. 2017, 13, 460-470. [CrossRef]

59. Savickas, M.L. Career construction theory and practice. In Career Development and Counseling: Putting Theory and Research to Work; Brown, S.D., Lent, R.W., Eds.; Wiley: Hoboken, NJ, USA, 2013; pp. 147-183.

60. Hirschi, A.; Herrmann, A.; Keller, A.C. Career adaptivity, adaptability, and adapting: A conceptual and empirical investigation. J. Vocat. Behav. 2015, 87, 1-10. [CrossRef]

61. Koen, J.; Klehe, U.C.; Van Vianen, A.E. Training career adaptability to facilitate a successful school-to-work transition. J. Vocat. Behav. 2012, 81, 395-408. [CrossRef]

62. Duffy, R.J. Putting Children First: A Framework for Change in School Governance; Mayor's Office: Rochester, NY, USA, 2010.

63. Negru-Subtirica, O.; Pop, E.I. Longitudinal links between career adaptability and academic achievement in adolescence. J. Vocat. Behav. 2016, 93, 163-170. [CrossRef]

64. Pucciarelli, F.; Kaplan, A. Le università europee oggi: Sfide e nuove strategie (European universities today: Challenges and new strategies). E M 2018, 1, 85-95.

65. Yáñez, S.; Uruburu, Á.; Moreno, A.; Lumbreras, J. The sustainability report as an essential tool for the holistic and strategic vision of higher education institutions. J. Clean. Prod. 2019, 207, 57-66. [CrossRef]

66. Cohen-Scali, V.; Pouyaud, J. A Career Education Approach Based on Group Dialogues to Help Adolescents and Emerging Adults in Their Self Construction. In Handbook of Innovative Career Counselling; Maree, J., Ed.; Springer: New York, NY, USA, 2019; pp. 405-424.

67. Roy, A.L.; Raver, C.C.; Masucci, M.D.; DeJoseph, M. "If they focus on giving us a chance in life we can actually do something in this world": Poverty, inequality, and youths' critical consciousness. Dev. Psychol. 2019, 55, 550-561. [CrossRef] 
68. Arulmani, G. Striking the right note: The cultural preparedness approach to developing resonant career guidance programmes. Int. J. Educ. Vocat. Guid. 2011, 11, 79-93. [CrossRef]

69. Santilli, S.; Ginevra, M.C.; Di Maggio, I.; Nota, L. Developing and promoting inclusion from kindergarten to university. In Promoting Social Inclusion; Scorgie, K., Forlin, C., Eds.; Emerald: Bradford, UK, 2019; pp. 55-71.

Publisher's Note: MDPI stays neutral with regard to jurisdictional claims in published maps and institutional affiliations.

(C) 2020 by the authors. Licensee MDPI, Basel, Switzerland. This article is an open access article distributed under the terms and conditions of the Creative Commons Attribution (CC BY) license (http://creativecommons.org/licenses/by/4.0/). 